\title{
UNILATERAL EXTERNAL AUDITORY CANAL ATRESIA WITH CONGENITAL FACIAL NERVE PALSY: A CASE REPORT
}

S. Venkata Ramana Raoํㅡㄹ V. S. Sharma², M. V. Subba Rao ${ }^{3}$, Pravin Tez ${ }^{4}$

\section{HOW TO CITE THIS ARTICLE:}

S. Venkata Ramana Rao, V. S. Sharma, M. V. Subba Rao, Pravin Tez. "Unilateral External Auditory Canal Atresia with Congenital Facial Nerve Palsy-A Case Report". Journal of Evolution of Medical and Dental Sciences 2015; Vol. 4, Issue 59, July 23; Page: 10402-10405, DOI: 10.14260/jemds/2015/1501

ABSTRACT: Congenital facial palsy is generally due to developmental anomaly or acquired cause. Unilateral congenital facial palsy due to developmental defect is most often associated with inner ear abnormalities. We report a rare case of unilateral congenital facial palsy with atresia of pinna and external auditory canal and normally developed middle ear and inner ear structures. ${ }^{1}$

KEYWORDS: Congenital facial nerve palsy, External auditory canal atresia, Bell's palsy, Microtia.

INTRODUCTION: Congenital facial nerve palsy associated commonly with inner ear abnormalities. The presentation of congenital facial palsy with external ear canal atresia and normal middle and inner ears is a rare presentation.

CASE REPORT: A 17years old male patient presented to ENT OPD with facial asymmetry, absence of right ear since birth. Patient did not seek any medical advice since birth. There is no history of Intrauterine birth infection, Prolonged labour and there is no premature delivery.

ON EXAMINATION: Patient has Right atresia of external auditory canal with preauricular tag, Right LMN Type of facial palsy with Bells phenomenon. Left ear is normal on examination and other cranial nerves on examination are normal.

Tuning Fork Test: Weber is lateralized to right ear.

\section{C.T SCAN TEMPORAL BONE:}

\section{Right Ear:}

- Hypoplasia and hypopneumatisation with sclerosis of right mastoid air cells.

- Right external auditory meatus is not made out- atresia.

- Soft tissue density is seen in the mesotympanum.

\section{Left Ear:}

- External auditory meatus is normal.

- Left mastoid air cells are normal.

- Left middle ear cavity structure appears normal.

DISCUSSION: According to Bobby R. ALFORD study of 118 cases of aural atresia prevalence of ear abnormalities with facial palsy is seen in $13 \%$ of cases where as inner ear abnormalities are seen in $22 \%$ of cases. Incidence of facial palsy in live births is $0.8-2.1 / 1000$ live births of these $88 \%$ are associated with difficult labour. ${ }^{2}$ developmental cause of facial palsy is mobeius syndrome where facial palsy is associated with lateral rectus palsy. Unilateral aural atresia associated with facial palsy is rare congenital facial palsy may cause multiple problems in new born like difficulty in nursing, eyeclosure, 
development of speech, expression of emotion, mastication. The physical examination is intended to exclude other syndromes like extra ocular muscle palsy, cleft palate and internal organs. Another congenital abnormality associated with facial palsy is that of maxilla like cleft palate, hyoplastic mailla, duplicatiom of palate.

Atresia, microtia with facial palsy are associated with inherited defects or acquired embyopathies owing to intrauterine infection like TORCH or exposure to toxins.

Embryonic insult due to toxins is severe can also produce abnormalities of other organs in addition to atresia like inner ear abnormalities

Deformities of canalisation of auditory canal are associated with deformities of pinna. The time for intervention of atresia along with facial palsy is debatable.

Sometimes facial palsy is associated with wide spectrum of congenital anomalies that involve structures from Ist and IInd arch Goldenhar syndrome is oculo-auriculo-vertebral dysplasia with congenital facial palsy. ${ }^{3}$

Most frequent cause of congenital facial palsy is birth trauma related to difficult delivery. Risk factors include forceps delivery, birth weight $>3.5 \mathrm{~kg}$, primiparity, injury to facial nerve vertical segment by the posterior blade over the mastoid. ${ }^{4}$ Facial nerve is susceptible to trauma as it exits from stylomastoid for a men where soft tissue compression can lead to damage of facial nerve (CHARGE Syndrome). Deformities of canalisation of auditory canal can lead to deformities of pinna. ${ }^{5}$

In addressing congenital facial palsy, some medical professionals advise initial surgery during preschool to avoid psychosocial problems associated with physical abnormality. However waiting till adolescence when facial growth is mature and child is able to understand the risks and benefits of surgery has merit. 6

Muscle transplantation for facial palsy is effective but better results are observed in case of traumatic facial palsy and reconstruction of auditory canal and pinna has to be taken when planning for muscle transplantation surgery with facial palsy. ${ }^{7}$

In this case as middle ear and inner ear is well developed the case is planned for reconstruction of ear canal and pinna. Facial palsy cannot be corrected as patient has reported late.

Fig. 1: Frontal view-Congenital facial palsy right side with aural atresia showing deviation of angle of mouth.

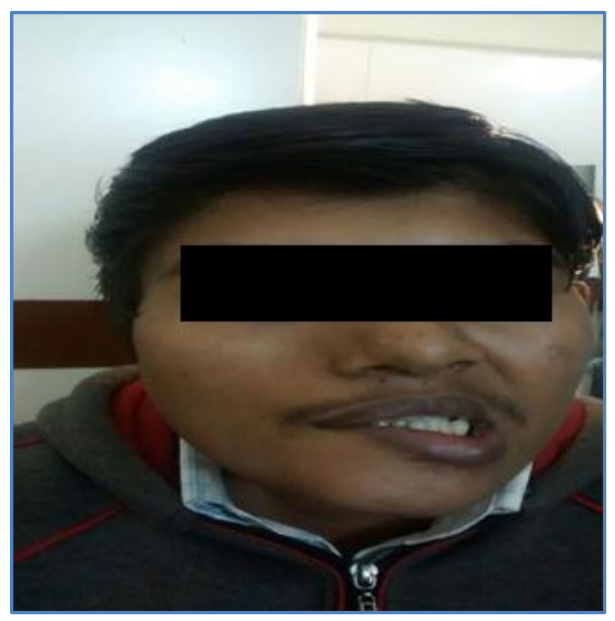

\section{Fig. 1}




\section{CASE REPORT}

Fig. 2: Lateral view showing Right aural atresia with preauricular tag.

Fig. 3: Bell's phenomenon.

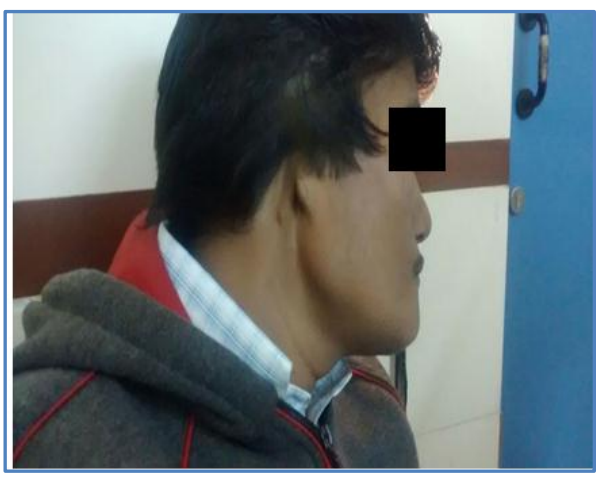

Fig. 2

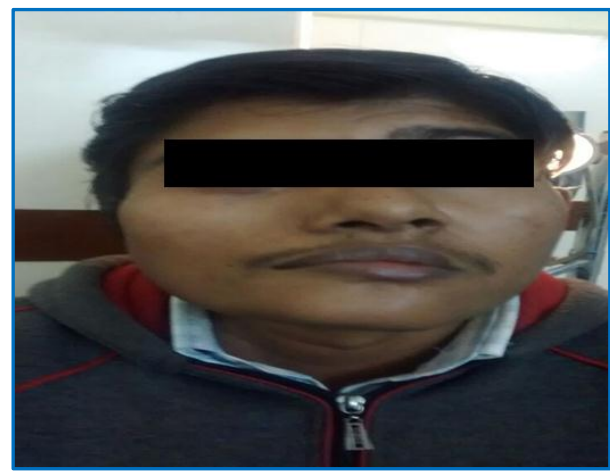

Fig. 3

Fig. 4: CT SCAN picture showing Right external canal atresia.

Fig. 5: CT SCAN picture showing Right middle ear and inner ear normal with atresia of external auditory canal.

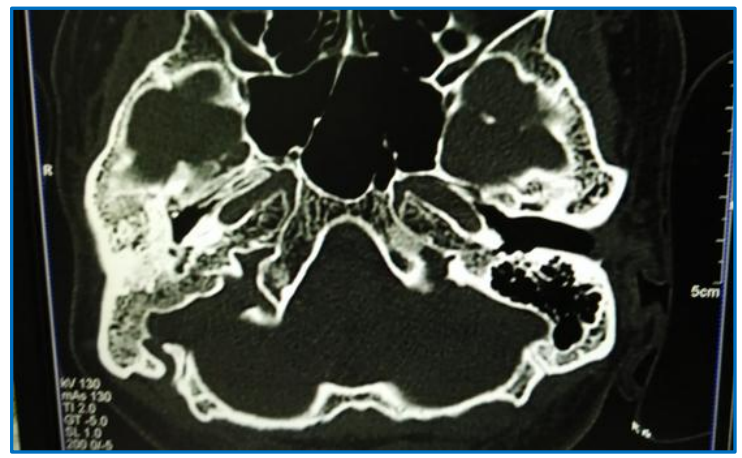

Fig. 4

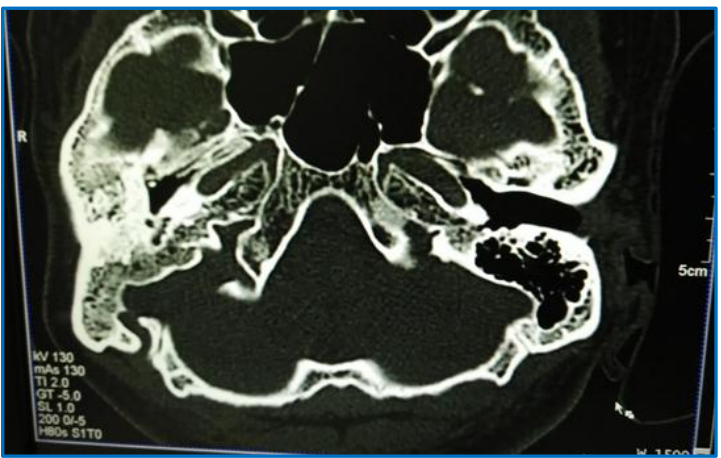

Fig. 5

\section{REFERENCES:}

1. Bergstrom L, Baker BB. Syndromes associated with congenital facial paralysis. Otolaryngol Head Neck Surgery 1981; 89(2): 336-42.

2. Falco NA, Eriksson E. Facial nerve palsy in the new born: incidence and outcome. Plastic Reconstr Surg 1990; 85(1): 1-4.

3. Jemec B, Grobbelaar AO, Harrison DH. The abnormal nucleus as a cause of congenital facial palsy. Arch Dis Child 2000; 83(3): 256-8.

4. Smith JD, Crumley RL, Harker LA. Facial paralysis in the newborn. Otolaryngol Head Neck Surg 1981; 89(6): 1021-4.

5. Parisier SC, Fayad JN, Kimmelman CP. Microtia, canal atresia, and middle ear anomalies. In: Ballenger's Otorhinolaryngology Head and Neck Surgery. 16 th edition, Snow JB, Ballenger JJ (Eds.), Williams \& Wilkins: Spain 2003: p.997-9.

6. Harrison DH. Treatment of infants with facial palsy. Arch Dis Child 1994; 7(3): 277-80. 


\section{CASE REPORT}

7. Zuker RM, Goldberg CS, Manktelow RT. Facial animation in children with Mobius syndrome after segmental gracilis muscle transplant. Plast Reconstruction Surg 2000; 106(1): 1-8; discussion 9.

\section{AUTHORS:}

1. S. Venkata Ramana Rao

2. V. S. Sharma

3. M. V. Subba Rao

4. Pravin Tez

\section{PARTICULARS OF CONTRIBUTORS:}

1. Professor, Department of ENT, Mediciti Institute of Medical Sciences, Medchal, Hyderabad.

2. Assistant Professor, Department of ENT, Mediciti Institute of Medical Sciences, Medchal, Hyderabad.

3. Professor \& Head, Department of ENT, Mediciti Institute of Medical Sciences, Medchal, Hyderabad.

FINANCIAL OR OTHER COMPETING INTERESTS: None
4. Resident, Department of ENT, Mediciti Institute of Medical Sciences, Medchal, Hyderabad.

\section{NAME ADDRESS EMAIL ID OF THE} CORRESPONDING AUTHOR:

Dr. S. Venkata Ramana Rao, 8-53/2, North Kamala Nagar, ECIL Post, Hyderabad, Telengana-500062.

E-mail: syamjivenkat19@ymail.com

Date of Submission: 27/06/2015. Date of Peer Review: 29/06/2015. Date of Acceptance: 13/07/2015. Date of Publishing: 23/07/2015. 